according to the woof of function. The value of this speculation, if it have any, is only as leading to investigation of disease, according to an anatomical method. I ask: Do the symptoms of temporary failures of function admit of being placed in an order according to what is known of the physiological relations of functional divisions and arterial (nutritive?) regions? It must be kept in mind, that most of our so-called knowledge of epilepsy is very speculative. And I think we should try to get rid of all those speculations which, although they give ease and comfort by "explaining things", have not in themselves the vitality to open out more work.

I have no doubt wandered far from the general subject of this paper; but a careful study of disease shows, that we must learn how the nervous system can suffer, if we wish to know what a particular get of symptoms means, rather than what it should be called.

[To be continued.]

\section{CASES ILLUSTRATIVE OF THE USE OF BATHS IN THE TREATMENT OF DISEASE.}

By Grorge B. Mead, M.D., Ph.D., M.A., E.R.C.P. Lond., etc., Newmarket.

Case I. Rheumatic Fever. John B., Newmarket, aged 30, employed at the Gas Works, was attacked in November 1865 with rheumatic fever, and was bedridden several months. He gradually recovered; and in April attempted to return to his work, but after very few hours found himself quite unable, and had a severe relapse in consequence of his effort to do so. The pains were most severe all over his body and limbs, and his joints became so rigid he was scarcely able to walk. He was ordered to take the improved Turkish bath at $120^{\circ}$, with feet in hot mustard and water, followed by the warm douche and partial cold douche, twice a week, and tepid followed by cold sheet every morning at rising, and a mild dose of antacid saline three times a day.

After the first bath, all pain and much of the stiffness left him. While in it, he perspired most freely. The perspiration had a very peculiar sour smell and highly acid reaction. A bath was given every third or fourth day, gradually raising the heat to $160^{\circ}$, and the cold douche prolonged. After a few baths, he was able to walk with comfort six miles at a stretch. He has much improved in "health and appetite; and is quite free from pain, and quite enjoys the bath.

The effect of the bath in improving the firmness of the muscles and healthiness of the skin was remarkable. His general health and appetite also very much improved.

The baths were continued with slight modifications for three weeks. At the end of that time, he was quite well, and returned to his employment, where he has continued ever since.

CASE Ir. Rheumatic Fever. C. F., aged 35, labourer, near Newmarket, had, ten years since, a severe attack of rheumatic fever. He was bedridden and helpless for months, suffering the most violent pain. It took him nearly a year to get over it.

The present attack came on in the beginning of May 1866. It began with rigors, great heat and thirst, restlessness, followed by severe pains attacking all the joints with such extreme tenderness that the slightest motion was attended by intolerable anguish. The joints were puffy; the tongue covered with white fur; pulse sharp and incompressible; urine scanty; bowels torpid; the skin was covered with unctuous perspiration of peculiar acid odour.
Examination of the heart shewed that it had been implicated in a previous attack, accounting for the occasional fits of numbness to which the patient was subject.

The portable hot air bath was ordered, with a magnesian saline aperient. The patient was kept in the bath twenty minutes, at the heat of $120^{\circ}$, and perspired very freely; the perspiration being most pangently acid. He was sponged over with warm water under sheets, and got quickly into a warm bed. He was ordered to be carefully sponged over with warm water night and morning, care being taken only to uncover part of the body at a time. He felt none the worse for the bath ; and on the next visit his pulse was found to be softer, the kidneys and bowels acting freely; all the signs of acute inflammation had subsided, and he had slept well; he was perfectly free from pain, and had partly recovered the use of his limbs. After a week, a second bath was given; and his improvement was so rapid that in a few days he was able to get out of doors, and expressed himself highly delighted with the treatment and result. He has since continued to improve, and is now suffering from debility only.

KrmarKs. In this case, the debilitated state of the patient, and the injury to the heart from the former attack, rendered imperative the greatest caution in the use of the bath; therefore, it was only used for a short time, and at long intervals. The result shews that, even where the heart has previously sustained injury, its use is perfectly safoindeed, tends to ward off disposition to cardiac affection. The patient's blood was loaded with morbid poison, which Nature was seeking to eliminate by the skin and kidneys. By the assistance to the natural powers of these organs afforded by the bath, more poison was eliminated in a day than, without its help, could have been thrown off in a month; hence the disease was enabled to run its course quicker; and, instead of the sufferer being in agonising pain for weeks and slowly recovering, his sufferings were speedily terminated, and a cure effected in Nature's own way.*

A gentleman, now in the most robust health, some years back, when reduced to an almost hopeless condition, was cured by similar means in a very few weeks, after all other remedies had failed, and may be referred to, so satisfied is he of the value of the means which he justly says " saved his life."

Cage III. On Monday, May 16th, 1866, at 10 A.M., Dr. Mead was requested to visit a stable-lad in Newmarket, who had been for a day or two complaining of pain and difficulty in swallowing, for which a saline mixture with acid gargle had been used.

There were redness of the velum, uvula, and fauces; restlessness and anxiety; difficulty of deglutition, each attempt being attended with sharp cutting pain; the act of inspiration was protracted, whistling with throttling noise. The voice was a hoarse whisper; the countenance anxious, ghastly; the eyes protruded; there was a painful sense of suffocation. The cough was harsh, stridulous, and husky. There, was great tenderness of the laryngeal cartilages; which were painful on pressure. Pulse 120, hard; skin hot and dry.

The patient was stripped, placed in a chair, and enveloped in blankets, with his feet in hot mustard and water, and hot fomentation-cloths around the throat, and, by means of the portable apparatus, subjected to a heat of $130^{\circ}$ Fahrenheit. After about ten minutes, copious perspiration was caused, with feel-

* The apparatus used was invented by Dr. Mead; it is portable, and, by a very simple contrivance, allows a ready adjustment of the heat. 
ing of sensible relief. After fifteen minutes longer, he was placed upright in a shallow bath and drenehed with tepid water, enveloped in dry sheet, rubbed dry, and put into a warm bed, when the pulse was found to be 90 ; the pain nearly gone; and the breathing essier. He swallowed some aperient medicine with very little difficulty.

When he was visited three houns afterwards, it was found that he had perspired freely since his return to bed, and was in all respects better. Pulse 85 . He was ordered a second dose of aperient medicine.

At the evening visit, the pulse was 80 ; skin moist; bowels not opened. He was ordered to take two aperient pills and saline mixture every four hours.

May 17th. He had a good night. The bowels acted early in the morning, without pain. Pulse 80 ; skin moist. He took soft food readily, swallowing without difficulty.

May 18th. He continued to improve, and by the end of the week was able to resume his employment.

Remarks. This treatment and its success will bear most favourable contrast with that recommended by any medical author. It afforded immediate relief. In less than two hours, the patient might safely be pronounced out of all danger. The rapid recovery that ensued was owing to Nature's vital powers not having been sapped by violent bleeding or strong mineral medicines. A physician, subject to sudden and violent attacks of this dangerous disorder, has several times obtained immediate relief in this manner; and there is no doubt that, if laryngitis be treated thus, a fatal issue is almost impossible.

\section{REMARKS ON THE CONSTITUTION OF THE MIND; AND ON UNSOUND- NESS OF MIND.}

By Frederick James Brown, M.D., Rochester.

MrND is the term used for the faculties of personal spirit acting in conjunction with living organic matter. The existence of mind apart from matter belongs to theology. Physiology and psychology recognise mind in conjunction with matter, and in this condition only. The physician observes the mind to be mastered by somatic conditions in delirium, and the body to be mastered by the mind in violent emotions and in impulses. Influence of mind and body, mutually, is a matter of daily experience.

The human mind is constituted of numerous faculties, grouped under the Understanding, the Will, the Affections, and the Moral Sense or Conscience.

Insanity is an abnormal condition of the judgment, under which this faculty loses its freedom. Delusions arise from distortion of the subjective and objective impressions; and erroneous conclusions arise from distortion of the intellectual conceptions. The mind is unsound because the judgment, that habitually balances the faculties, is disordered. So long as the judgment continues sound, unsoundness in one faculty may be corrected by another faculty, or at least may be acknowledged. Spectres that are not credited are instances of this kind; whilst, if believed in, they are hallucinations, and constitute mental unsoundness.

Insanity usually, perhaps invariably, is preceded and accompanied by unsoundness of the affections. The will may continue free, or may become affected; and the same holds good with the conscience. Sometimes the conscience is first affected, next the affections.

I have watched perversion of the will occurring in males. One boy recovered after three months. A young man recovered after many years. The judg- ment was not affected, except that it gave no response to argument; but, in cases of perversion of the will, the judgment is unfettered, and the affections suppressed voluntarily ; and the observer must be keen to note changes of countenance and gesture, whilst arguing and appealing to reason and feelings.

Possibly insanity may commence in disorder of the will in some cases, the affections suffering next in order.

When the affections are unsound without implication of the judgment, the individual is not mentally unsound : therefore the term moral insanity is not correct. Yet the affections are unsound. The individual knoros, but does not feel, the difference between what is right and what is wrong. Some persons do not feel the sanctity of human life, and would as lief take the lives of their fellow-men as of vermin. Knowledge of what the world esteems right and wrong alone restrains their hands. The same remark holds good in respect to regard for property; also in relation to the principles of justice, virtue, truth, and decency. In some men, there is absence of the principles of morality. The human mind, in such instances, appears to be constituted like those of brute animals. It is doubtful whether such be the fact; but the moral faculties are not developed. So long as the judgment be not implicated in unsoundness, such men are not mentally unsound. This is an axiom never to be lost sight of.

If sudden impulses arise in the mind of a man healthy in mind and body, self-control is demanded of him by society, and rightly so. But, if any of the faculties be unsound, is the mind capable of selfcontrol, in the event of sudden impulse? The condition of the judgment previously to the commission of crime must be inquired into, as well as its condition subsequently; otherwise a faulty conclusion may be arrived at. In some cases, the judgment is free both before and after the event, and is only overborne for the moment. One night I was called to see a woman who awoke maniacal at 1 A.M. She was quiet, but completely insane. In one hour she fell asleep, and awoke next morning well. She had suffered much domestic distress and privation. If she had strangled her bed-fellow, and had then gone to sleep and awoke in a sane state next morning, what then?

After these remarks, I return to the consideration of the commission of motiveleless crime by the children of lunatics. These individuals are sane, and may be divided into two categories : $a$. Those possessing all the faculties sound: $b$. Those that have certain faculties unsound. Both classes are liable to commit motiveless crime. The cause must be sudden impulse in class $a$. The same cause may operate in class $b$, or the judgment may grow tired of controlling and balancing ill-poised faculties.

Are the children of lunatics equally responsible with the children of sane persons? I trow not. There ought to be a compromise, in the way of punishment, between that appointed for sane persons and that for lunatics. Human responsibility is a variable quantity : it is never two days equal, from the cradle to the grave. Such being the case, allowance should be made for mental infirmity as an inheritance either actually or by predisposition. The rnind, equally with the body, is inherited; and the mind developes equally with the body. If there be arrest of any of the mental faculties, the individual deserves our pity, even when it becomes necessary to censure his conduct. The connexion between insanity, crime, drunkenness, etc., is well known; and the subjects of these horrors deserve our pity. 